
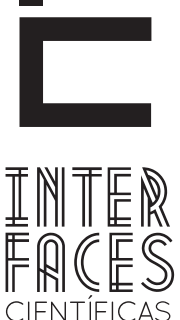

HUMANAS E SOCIAIS

ISSN IMPRESSO 2316-3348

ISSN ELETRÔNICO 2316-3801

\title{
A EDUCAÇÃo PARA A MÍDIA E A REVISÃO DO MITO MIDIÁTICO
}

Rafael Mota²

\section{RESUMO}

A educação para a mídia deve ser um fio comum que passe e perpasse por todas as áreas curriculares e viventes do ser humano, uma vez que se refere à comunicação e à sociedade. Só assim discerniremos com consciência os mitos midiáticos (artistas, políticos, jornalistas e etc.), dos mitológicos gregos. Este artigo pretende refletir sobre como a mídia apropria-se desta linguagem e de que maneira trazem a cena/constroem/reinscrevem o mito, além de tentar compreender qual seria o papel da educação na construção de uma consciência crítica que possibilite a construção de uma consciência crítica desse mito midiático. 0 presente estudo se debruça e desenvolve-se, tomando, por exemplo, mítico midiático a figura do jornalista brasileiro Paulo Francis.

\section{PALAVRAS- CHAVE}

Mídia. Educação. Paulo Francis.
Ronaldo Nunes Linhares ${ }^{2}$

\section{ABSTRACT}

The education for the media must be a common line that goes through all curricular areas and the living human being, since it refers to communication and society. Only then consciously discern myths media (artists, politicians, journalists and so on.), the greek mythological. This article aims to reflect on how the media appropriates this language and how they bring the scene/build/reinscribe the myth, besides trying to understand what would be the role of education in building a critical consciousness that enables the construction of a critical awareness of this media myth is that this study focuses and develops, taking, for example, the media mythic figure of Brazilian journalist Paulo Francis.

\section{KEYWORDS}

Media. Education. Paul Francis. 


\section{RESUMEN}

La educación para los medios de comunicación debe ser un hilo común que atraviese todas las áreas del currículo y de vida del ser humano, ya que se refiere a la comunicación y a la sociedad. Sólo entonces podremos discernir conscientemente los mitos de los medios de comunicación (artistas, políticos, periodistas, etc.), de la mitología griega. En este trabajo se desea reflexionar sobre cómo los medios de comunicación se apropian de este lenguaje y cómo traen a la escena / construyen / reinscriben el mito, además de tratar de entender cuál es el papel de la educación en la construcción de una conciencia crítica que permita la construcción de una conciencia crítica de ese mito relacionado a los medios de comunicación, en eso se centra y desarrolla este estudio, teniendo, por ejemplo, la figura del mítico periodista brasileño Paulo Francis.

\section{PALABRAS CLAVE}

Medios de comunicación. Educación. Paulo Francis.

\section{INTRODUÇãO}

Qual o papel da mídia na construção de um mito? Os mitos podem ser tanto os olimpianos, de que fala Morin (1975), quanto àqueles personagens alçados a bel prazer a essa condição de super estrelas pela imprensa. É, justamente, com o intuito de investigar como a mídia apropria-se desta linguagem e de que maneira traz a cena/constroem/reinscrevem o mito, além de tentar compreender qual seria o papel da educação na construção de uma consciência crítica que possibilite a construção de uma consciência crítica desse mito midiático, é que o presente estudo se debruça e desenvolve-se, tomando, por exemplo, mítico midiático a figura do jornalista brasileiro Paulo Francis, mito este construído durante boa parte de sua vida profissional e ampliado no período de sua morte pelos principais veículos de comunicação do Brasil.

Neste artigo no primeiro tópico, Mídia e a construção dos Mitos, serão discutidas o papel e a contribuição da imprensa no processo de fabricação do mito moderno. Subsequentemente tratar-se-á da relação imprensa e Paulo Francis ou "dos mortos não se fala a não ser bem”, quando se mostrará, através da análise feita sobre as matérias de jornais, revistas e sites, pu- blicadas no período da sua morte, como foi construída e alicerçada a imagem mítica do jornalista Paulo Francis.

Por fim, procurar-se-á construir uma reflexão sobre como a educação para os meios pode exercer um papel de destaque na construção consciente e crítica para uma visão midiática, sem que para isso precise relegar a importância da imprensa e das novas mídias como ferramenta importante e aliada de um novo processo educacional.

Desde a Antiguidade as sociedades criam seus mitos. 0 mito foi, e ainda hoje o é, uma forma que as comunidades humanas encontraram para poder explicar suas contradições, exprimir seus paradoxos, dúvidas e inquietações. Oliveira (2001, p. 11) evidencia que o mito aparece nas primeiras civilizações como "tentativas de compreender o fenômeno das forças sociais que se baseavam na imaginação, na fantasia, na especulação".

Edgard Morin, teórico francês das décadas de 1960 e 1970, em seu livro Cultura de Massas no Sé- 
culo XX (1975), definiu como um fenômeno presente da comunicação industrializada o surgimento do culto aos mitos formados a partir da disseminação da mídia, que se constituem verdadeiros “deuses” do Olimpo moderno. No capítulo intitulado "Os Olimpianos", o estudioso mostra que atores de cinema, expoentes das artes, astros dos esportes, políticos

\section{A MÍDIA EXERCE OS "SEUS PODRES PODERES"}

A cultura de massa fornece à vida privada as imagens e os modelos que dão forma às inspirações do homem comum (MORIN, 1975) e toma de empréstimo a terminologia mítica para referir-se às personalidades midiáticas. À primeira vista, parece que a comunicação tomou para si o conceito antropológico de mito para referir-se à produção contemporânea.

Originalmente usado como forma de compreensão de fenômenos ocorridos nas sociedades tradicionais, o mito é definido como narrativa exemplar que pretende explicar a origem do mundo e o seu funcionamento. De acordo com Pierre Ansart (1978), tanto as sociedades modernas, como as sociedades tradicionais, produzem seus imaginários sociais, seus sistemas de representações, através dos quais elas estabelecem simbolicamente suas normas e seus valores. É compreensível, portanto, que a fim de entender os processos de criação simbólica - já que esses nem sempre são conscientes e racionais - o homem contemporâneo faça uso de significantes que lhes são, a um só tempo, próximos e distantes, modificando lhes o significado.

De acordo com Jung (1993), os arquétipos são estruturas características da camada mais profunda do inconsciente: o supra pessoal ou coletivo. Nele estaria marcada toda a evolução da psique humana, toda sua história desde os primórdios da humanidade. Essas estruturas, possivelmente, seriam sedimentos atuantes, a realeza e suas cortes, líderes religiosos e muitas outras personalidades são alçadas à condição de seres "superiores", num processo alucinante que vende jornais, sustenta a publicidade, movimenta as marcas de produtos de toda a ordem, e os mantém como criaturas acima do bem e do mal, para efeitos consumistas.

de experiências repetidas pelos homens ao longo do tempo. Não são experiências pessoais, mas de nossos ancestrais, coletivas, que dizem respeito a toda raça humana e que são herdadas por nós. Todavia, Jung faz questão de frisar que não são as imagens que são herdadas, mas apenas a "aptidão para reproduzir as mesmas ideias míticas” (JUNG, 1993, p. 61).

Para Humberto Eco (1987) as personagens míticas da cultura de massa são a soma de certas aspirações coletivas, estas aspirações as quais o pensador italiano denomina arquétipos. Segundo Eco, são exatamente as aspirações coletivas, conscientes ou inconscientes, que as personagens midiáticas corporificam e por isso tornam-se mitos, figuras aglutinadoras do imaginário de determinada época. A identificação necessária entre a personagem midiática e o público se dá justamente na "humanidade" daquela.

Em matéria publicada pela revista Superinteressante sobre a criação do mito, explica que a fama permite a criação de uma espécie de personagem permanente (SOALHEIRO; FINOTTI, 2004). De acordo com o texto, o ídolo precisa ter certas características que o distanciam dos simples mortais, alguém com habilidades extraordinárias, residente do Olimpo. Mas até o mito hoje é massificado, segundo Tognolli (2003). Um exemplo disso seria os programas chamados reality shows, onde pelas câmeras de TV, podem-se ver pessoas antes anônimas, transformarem-se em celebri- 
dades ao mostrar suas rotinas diárias, como dormir comer, escovar os dentes. Seria a versão moderna do romance "1984", de George Orwell, um Big Brother pós-moderno. E não para por aí, as redes sociais a exemplo do Orkut, Facebook, também exercem esse papel psicótico de tornar você um pouco famoso de você mesmo, agrupando seres comuns pelo que eles têm em comum, num compulsivo ciclo narcisístico de autoadoração.

A matéria-prima da notícia é o raro, o paradoxo, o imprevisto e o caos, aparente ou verdadeiro, diz Serva (2001). 0 autor explica que essa rede de notícias trabalhando sempre em busca da novidade, tira do público a capacidade de avaliação e compreensão das informações e "possivelmente anula a sua capacidade de produzir signos interpretantes necessários para o acompanhamento de todas as notícias" (SERVA, 2001, p. 79). Leão (1997) afirma que os consumidores ficam hipnotizados diante da imprensa.

0 poder midiático, sobretudo o poder exercido pela mídia na população brasileira é incomensurável. A formação do mito através da mídia perpassa por essa absorção da informação, sem uma maior deglutição por parte da população, que sem discernimento absolve a notícia sem questionar os valores políticos e econômicos atrelados àquela informação. A imprensa sempre usa de um discurso que faz da eloquência,

\subsection{CONSTRUINDO UM OBITUÁRIO A IMPRENSA E PAULO FRANCIS OU DOS MORTOS NÃO SE FALA A NÃO SER BEM}

Franz Paul Trannin da Matta Heilborn nasceu em 1930 na cidade do Rio de Janeiro. Teve a sua educação fundamental e o secundário em colégios católicos tradicionais do estado da Guanabara. Já Paulo Francis nasceu em 1951, batizado por Paschoal Carlos Magno que, considerando impronunciável o sobrenome Heilborn, sugeriu Francis. Paulo aceitou, "Por que achava que aquela brincadeira jamais passaria dos limites da casa dele" (FRANCIS. 1981). Neto de alemães, Francis arma política, valendo-se de retórica intempestiva e emocionada para convencer a população a comprar a ideia vendida por ela, a detentora da verdade.

Faz-se necessária uma alfabetização crítica da mídia, uma resposta educacional que amplie a noção de alfabetização, incluindo diferentes formas de comunicação de massa, cultura popular e novas tecnologias. Algo que aprofunde o potencial da alfabetização na análise crítica entre a mídia e as audiências, informação e poder.

Algo que cabe melhor análise e observação é a produção de mídia alternativa. Ela fornece aos alunos o poder de criar suas próprias mensagens, desafiando os próprios textos midiáticos. Os blogs quando não simplesmente reverberam as grandes mídias e reproduzem as suas palavras, é um bom exemplo disso, o leitor antes passivo, agora passa a escritor ativo dos seus textos. Jenkins (2006) afirma que o maior problema para os educadores hoje não é a velha noção de uma divisão digital que separa as pessoas de acordo com o seu acesso às ferramentas de comunicação, uma vez que existe hoje um número nunca antes visto de pessoas que têm acesso a elas. "Precisamos reavaliar os objetivos da educação midiática, para que os jovens possam se vê como produtores culturais e participantes, e não simplesmente como consumidores críticos ou não" (JENKINS, 2006, p. 259).

começou sua carreira jornalística como crítico teatral e com elas, no Dário Carioca entre 1957 e 1963, acabou mudando o panorama teatral brasileiro.

A partir de 1963 desvia seu furor Trotskista para outro foco de alcance mais alto e amplo que o teatro: a política. Com uma forma de escrever coloquial e agressiva. Considerada por muitos, como crítica pessoal, ele tornou-se o "polemista profissional”. Dizia 
verdades definitivas sobre física quântica. Foi assim que o necrológio da revista Veja edição n¹482 de 12 de fevereiro de 1997 apresentava o Jornalista Paulo Francis. Capa da principal publicação do país, Paulo Francis que falecera em 04 de fevereiro de 1997 era considerado o mais polêmico jornalista dos últimos 50 anos na imprensa brasileira. Para os inimigos não passava de grosso, destemperado, plagiário e preconceituoso. Para os amigos uma flor no contato pessoal, de aparente ranzinza a um bem humorado, moleque.

Com mais de quarenta anos na imprensa, ninguém nunca passou imune a sua argúcia, cultura, conceitos, pré-conceitos e verve cortante. De ator frustrado, passando por revolucionário da crítica cultural brasileira, chegando à editoria política. Era assim, um ser multifacetado, dicotômico, superlativo, que transitava entre o "lobo hidrófobo" e um gentleman.

Se durante a vida Paulo Francis lutou incessantemente por um reconhecimento literário, durante a morte certamente ele o alcançou. Os textos publicados pela imprensa foram recheados de adjetivos, o governo decretou luto oficial, bandeira a meio pau, nota da Presidência, pétalas de rosa jogadas do helicóptero, inserções no Jornal Nacional, tudo digno de um herói nacional. Até a esquerda já tão nocauteada por ele, perfilou-se diante do caixão e prestou solidariedade.

Paulo Francis foi sepultado com todas as honras que thes eram merecidas, seja como pessoa pública ou como personagem indispensável da imprensa brasileira. Mas os exageros cometidos pela imprensa revelaram a dificuldade das redações em produzir textos com maior profundidade em se tratando de assunto e personagem tão polêmico sem que para isso soasse corporativista.

0 período durante o regime militar foi um dos momentos mais controversos e inquietantes vividos por Paulo Francis durante a sua carreira de jornalista e intelectual. Talvez por não querer comprometer o jor- nalista já morto, a imprensa brasileira usou a máxima Shakespiriana em que, “dos mortos não se fala a não ser bem", e simplesmente ignorou uma das mais conturbadas fases de Paulo Francis, além tentar minimizar todos os preconceitos e o hábito de não checar fontes do jornalista, o que por vezes resultou em erros homéricos.

Em nenhum momento foi buscado entender como um esquerdista ferrenho pôde tornar-se maior defensor das direitas e do imperialismo americano. Nos impressos estudados não há aprofundamento na história e na realidade brasileira para fundamentar dados e informações mais relevantes de uma vida tão rica de um ser humano tão controverso, capaz de expor e se expor por vezes com tamanha crueldade. Os jornais e revistas somente reproduziram opiniões sustentadas no opinionismo emocionado dos amigos, que minimizaram seus modos e erros enquanto excederam na grandiosidade. A principal publicação semanal do país na edição de 12 de fevereiro de 1997 traz em dois boxes depoimentos emocionados, dos amigos Ivan Lessa e Diogo Mainardi.

\begin{abstract}
A mais brilhante contundência. Tudo que poderia se dizer de Paulo Francis já foi dito, para variar, dito antes por Paulo Francis. Recuso-me a segurar na alça do caixão do fraternal amigo diante de tanta gente estranha. (LESSA, 1997).
\end{abstract}

\begin{abstract}
Era curiosa a religiosidade de Francis. Em 1995 em Veneza, assistimos à missa do Galo na catedral de São Marcos. Comoveu-se com os mosaicos iluminados, com os ornamentos sagrados. Assim que o bispo começou a sua ladainha, Francis fechou os olhos e tirou uma soneca. (MAINARDI, 1997).
\end{abstract}

Com a morte de Paulo Francis foi possível observar o quão corporativista foi a imprensa do eixo Rio - São Paulo. Os defeitos do jornalista foram sempre descritos de forma rápida, qualidades verdadeiras foram realçadas e outras meramente supostas agregadas. A revista Veja é um exemplo dessa aceitação pouco critica sobre o jornalista. Nos comentários a seguir podemos observar exemplos deste posicionamento. 
Exibia-se como um pavão para as câmeras de TV, mas era de uma timidez atroz. (Revista Veja edição $n^{\circ}{ }^{1482}$ ) Grosso, agressivo e destemperado por escrito, era uma flor no contato pessoal. (Revista Veja edição n 1482) Tinha dezenas de amigos, mas dava a impressão de ser um solitário. (Revista Veja edição n¹482)

$\mathrm{O}$ aparente ranzinza tinha um humor de moleque. (Revista Veja edição n¹482)

A capa com uma foto em close de Paulo Francis quase em posição do pensador de Rodin traz em tom de sentença: "Ele vai fazer falta. A trajetória do mais debatido e exasperante jornalista brasileiro". Em nenhum momento a reportagem de sete páginas dos jornalistas Eurípedes Alcântara correspondente de Nova York, Neuza Sanches de São Paulo e Virginie Leite do Rio de Janeiro procurou os incontáveis desafetos que Francis ao longo da vida agrediu, em geral com termos nada afetuosos.

Não foi entrevistado Lula, Erundina, Itamar, Jaguar, Sérgio Cabral, Ruth Escobar, Caetano, Tônia Carreiro e tantos outros, por quê? Da mesma forma que não foi perguntada ou pedida à opinião de nenhum outro nordestino, índio, negro, gay e mulher também ofendidos por ele. Qual teria sido o critério adotado por essas publicações para definir a linha editorial a ser seguida? Por que a parcialidade na cobertura da morte de Francis? Os necrológios de pessoas famosas não deveriam explicar com a mesma intensidade e destaque as grandezas e as misérias do falecido, mesmo que para isso imagens sejam desconstruídas?

Em nenhuma das publicações houve uma tentativa de explicar uma vida tão contraditória, com mudanças tão radicais. Por que Francis de uma esquerdista radical, capaz de chamar Roberto Marinho no principal jornal alternativo da época, o Pasquim, de porcaria, imbecil e traidor se tornou no mais feroz jornalista de direita? 0 jornalista Sergio Augusto em reportagem do jornal Folha de São Paulo de 04 de fevereiro de 2007, tenta responder essa questão simplificando-a. Afirma o autor, "O ex-comunista é alguém que se sente traído, e ele passou a reagir assim, como se tivesse sido vítima de uma traição".
Por que não revelar a realidade de uma vida tão rica, de um ser com tamanha coragem de expor com tanta crueza seus ódios e preconceitos? Uma das poucas personalidades agredidas por Paulo Francis e ouvidas pela imprensa foi à atriz Tônia Carreiro que ironizou na sua declaração, publicada no Jornal o Globo, do dia 09 de fevereiro de 1997. "Nenhuma das iniciativas dele na área [do teatro] deu certo. Nem mesmo a de crítico" (Jornal O Globo, 1997).

Os defeitos do jornalista foram emblematicamente justificados por amigos, que em geral procuravam separar o homem do jornalista. No jornal $O$ estado de São Paulo de 05 de fevereiro de 1997, Nelson Mota, seu companheiro no programa Manhattan Connection, observa que "não se deve confundir Paulo Francis com o personagem Paulo Francis".

Em texto publicado na Folha de São Paulo em 05 de fevereiro de 1997 o jornalista Janio de Freitas escreve: "Um personagem inventado com o capricho e o talento do sempre apaixonado por teatro que à falta de uma peça sua para elaborar o grande personagem, criou-o na sua vida mesma..." (FREITAS, 1997).

Com o título "Ele foi um dos fazedores de cabeça das últimas décadas" a Folha de São Paulo de 04 de fevereiro de 1997 revela o poder que as opiniões expressadas por Paulo Francis na sua coluna tinham tanto para o bem quanto para o mal. "Se Francis demolia um filme, essa opinião era repetida à exaustão. Se elogiava também" (FREIRE, 1997) Aliás, essa não era uma opinião uníssona da Folha de São Paulo. Compartilhavam dessa opinião os demais veículos de comunicação.

Nenhum outro jornalista brasileiro neste século teve
tanto público e influência quanto Paulo Francis (Revis-
ta Veja edição n¹482).
Um dos mais influentes fazedores de cabeça das últi-
mas três décadas (Folha online $04 / 02 / 1997$ ).

Baseada nas declarações de amigos, as matérias insistem em ressaltar de forma superlativa a impor- 
tância do jornalista para a imprensa brasileira. É o que faz Matias Suzuki Jr. em matéria da Folha de São Paulo do dia 04 de fevereiro de 1997: "Paulo Francis foi o grande revolucionário do jornalismo brasileiro da segunda metade deste século... Ele foi o responsável por despertar a paixão pelo jornalismo em grande parte dos quadros que hoje estão nos postos chaves da imprensa no país..."

O que se viu na imprensa no primeiro momento pós-morte de Francis, foram somente textos opinati-

\section{MITO MIDIÁTICO E A EDUCAÇ̃̃O PARA MÍDIA}

A partir dos anos 1970, no mundo inteiro, a educação para as mídias vem se desenvolvendo, seus objetivos dizem respeito à formação de usuários ativos, críticos e criativo de todas as tecnologias de informação e comunicação. Em reuniões, sob os auspícios da Organização das Nações Unidas para a Educação, a Ciência e a Cultura (UNESCO), está presente a ideia essencial que a educação para as mídias é condição sine qua non da educação para a cidadania, sendo um instrumento fundamental para a democratização das oportunidades educacionais e do acesso ao saber e, portanto, de desigualdades sócias. (BELLONI, $1991 \mathrm{e}$ 1995).

Por que ensinar as mídias? Len Masterman (1993) aponta sete razões principais:

1-0 consumo elevado das mídias e a saturação à qual chegamos. 2-A importância ideológica das mídias, notadamente através da publicidade. 3-A aparição de uma gestão de informação nas empresas (agência de governo, partidos políticos, ministérios, etc.). 4-A penetração crescente das mídias nos processos democráticos (as eleições são antes de tudo eventos midiáticos). 5- A importância crescente da comunicação visual e da informação em todos os campos (fora da es- vos sem aprofundamento histórico que explicassem o homem além da criação, mistificação ou invenção da personagem. A imprensa se mostrou corporativista, condescendente e exagerada nos comentários e adjetivação positiva ao jornalista, sendo incapaz de exercer o manual básico do bom jornalismo que recomenda ouvir duas partes, e no caso de Paulo Francis se existiam amigos o número de inimigos ou desafetos era ainda maior.

cola que privilegia o escrito, os sistemas de comunicação são essencialmente icônicos). 6- A expectativa dos jovens a serem formados por compreender sua época (que sentido há em martelar uma cultura que evita cuidadosamente as interrogações e as ferramentas do seu tempo?) 7- 0 crescimento nacional e internacional das privatizações de todas as tecnologias da informação (quando a informação se torna uma mercadoria, seu papel e suas características mudam).

A educação midiática deve ser relacionada à educação para a democracia, estimulando os alunos a serem participantes informados e letrados midiáticos em suas sociedades. Além disso, a alfabetização midiática deve ser relacionada à alfabetização pela informação, à alfabetização tecnológica, às artes e às ciências sociais.

\footnotetext{
No entanto da mesma forma que é fundamental reconhecer a importância das novas tecnologias e a urgência de criar conhecimentos e mecanismos que possibilitem sua integração à educação, é também preciso evitar o "deslumbramento" que tende a levar ao uso mais ou menos indiscriminado das tecnologias por suas virtudes tecnológicas do que por suas virtudes pedagógicas. E não se trata de um discurso apocalíptico e sim ideológico mediante aos interesses da indústria e do setor. (BELLONI, 2001).
} 
O texto, o título, a foto e o posicionamento dela na página, tudo isso compõe o discurso jornalístico. Isoladamente analisados, cada um desses fragmentos oferece uma visão contextualizada e que compromete o discurso. No entanto, são esses fragmentos que revelam a verdade. Mesmo sendo o menor fragmento do discurso, a palavra com certeza é o que nos possibilita compreender melhor o texto.

\section{A GUISA DE CONCLUSÃO}

A imprensa, seja no Brasil ou em qualquer parte do mundo, continuará a criar e renovar seus mitos, até por que mitos são rentáveis e vendáveis nos dia atuais. Como disse (SOREL, 1992, p. 32) "os mitos são criações contemporâneas que com a ajuda propulsora da mídia tornou-se mercadoria".

Assim, como os mitos, a mídia mercantilizou objetos, pessoas e pensamentos. 0 homem tornou-se além de produto, um consumidor inveterado que a todo o momento é bombardeado por informações midiáticas que o convida ao consumo com um processo de sedução lento e eficaz, oferecendo estímulos de sonho e fantasia.

A estratégia midiática é fazer o individuo se identificar com os produtos, imagens e comportamentos veiculados, para depois adquiri-los, seja o figurino da novela, o tênis do jogador, a mansão do milionário ou as ideias do intelectual, político, artista, etc.
A alfabetização crítica da mídia deve ser um fio comum que passe e perpasse por todas as áreas curriculares e viventes do ser humano, uma vez que se refere à comunicação e à sociedade.
Um exemplo disso pôde ser observado neste trabalho com a construção do perfil mitológico de Paulo Francis por parte da imprensa. A todo o tempo, de forma superlativa foi evidenciado a grandiosidade do jornalista em detrimento aos seus erros. Mais que vender o homem, nesse caso tentou-se vender a ideia politica e econômica de um ser controverso, mas que para os amigos era pacífico, insuperável e restrito a poucos, ratificando assim a ideia inalcançável do mito.

No entanto o objetivo aqui exposto, não foi de demonizar as mídias e as novas tecnologias, afinal, quando bem usadas elas são aliadas da educação, mas de contribuir com uma discursão que amplie o papel das comunicações na educação do indivíduo, levando-o a sair de uma posição passiva de receptor, para uma ativa de emissor. A educação para as mídias vai além das salas de aula, ela educa e contribui para a formação de cidadão consciente e capaz de interpretar e decodificar mensagens, para que a partir daí decida compra-las ou não.

\section{REFERÊNCIAS}

ANSART, Pierre. Ideologias, Conflitos e Poder. Tradução de Aurea Weissenberg. RJ: Zahar, 1978

BELLONI, Maria Luiza. 0 que é Mídia - Educação. 2. ed. Campinas-SP: Autores Associados, 1991 e 1995. 
DUARTE, Jorge; BARROS, Antonio(Org.). Métodos e técnicas de pesquisa em comunicação. 2. ed. São Paulo: Atlas, 2005.

ECO Umberto. Apocalípticos e Integrados. Tradução de Pérola de Carvalho. SP: Perspectiva, 1987.

FERNANDES, Thareja. 0 mito midiático - um sobrevôo teórico [online]. Disponível em: <http://www.rp-bahia. com.br/trabalhos/paper/dissertacoes/o_mito_midiatico.pdf>. Acesso em: 25 set. 2011.

FRANCIS, Paulo. 0 afeto que se encerra - memórias. 3. ed. Rio de Janeiro: Civilização Brasileira, 1981.

FREIRE, Vinicius Torres. Ele foi um dos fazedores de cabeça das últimas décadas. Folha de São Paulo, 1997, fev. 4, p. 15.

FREITAS, Jânio. Morre o jornalista Paulo Francis. Folha de São Paulo, 1997, fev. 4, p.17.

JENKINS, H. Convergence culture: where old and new media collide. New York: New York University, 2006.

JUNG, Carl Gustav. Psicologia do Inconsciente. Tradução de Maria Luiza Appy. Petrópolis: Vozes, 1993.

LESSA, Ivan. Ele vai fazer falta. Revista Veja. São Paulo. Edição 1482, 1997, fev. 12, p.78 Disponível em: <http://veja.com.br>. Acesso em: dia/mês/ano.

MAIANARD, Diogo. Ele vai fazer falta. Revista Veja. São Paulo. Edição 1482, 1997, fev. 12, p.79 Disponível em: <http://veja.com.br>. Acesso em: dia/mês/ano.

MASTERMAN, Len. ¿Por qué? In: La enseñanza de los medios de comunicación. Madrid: Ediciones de la Torre, 1993, p. 15-32.

MORIN, Edgar. Cultura de massas no século XX - Neurose. 3. ed. R J: Forense Universitária, 1982.

Morre Paulo Francis. Jornal O Globo. 1997, fev. 4, p. 1

KELLNER, Douglas e SHARE, Jeff. Educação para a leitura crítica da mídia, democracia radical e a reconstrução da educação. [Online]. Disponível em: <http://www.scielo.br/pdf/es/v29n104/a0429104.pdf>. Acesso em: 24 set. 2011.

OLIVEIRA, Pérsio dos Santos. Introdução à sociologia. 24. ed. São Paulo: Ática, 2001.

PRATA, Nair. A mídia e o mito: uma análise do papel da imprensa mineira na construção da trajetória do estuprador da zona sul [Online]. Disponível em: <http://bocc.ubi.pt/pag/prata-nair-midia-mito.pdf-> Acesso em: 24 set. 2011.

PUGLISI, Maria Laura. Análise do Conteúdo. 3. ed. Brasília: Liber Livro, 2008 
SERVA, Leão. Jornalismo e desinformação. São Paulo: Senac, 1997

SOALHEIRO, Bárbara e FINOTTI, Ivan. Peão do Pop. Revista Superinteressante. Edição 198, mar. 2004, p. 23.

SOREL, Georges. Reflexões sobre a violência. São Paulo: Martins Fontes, 1992.

SOREL, Georges. Préface. In: SELIGMAN, E., L'Interprétation Économique de l'Histoire. Paris: Marcel Rivière $[\mathrm{s} / \mathrm{d}]$.

TOGNOLLI, Cláudio Júlio. Os mitos da mídia de celebridades. Disponível em: <http://www.observatoriodaimprensa.com.br/artigos/jd090920032.htm>. Acesso em: 24 set. 2011. 